\title{
Ethics Acculturation of International Counseling Students
}

\author{
Dan Li \\ University of North Texas, USA \\ Yang Ai \\ University of Redlands, USA
}

\begin{abstract}
Counseling ethics is a complex discipline; it is more than the acquisition of ethical principles, codes of ethics, and standards of practice. To disentangle the intricacies of ethics education, we use the acculturation model to conceptualize students' learning of counseling ethics, particularly international students who experience acculturation in the general sense and the acculturation of ethics in the counseling profession specifically. A case study is presented to illustrate the four acculturation strategies that students may adopt in ethical decision-making. Implications for counselor education, practice, and research are provided.
\end{abstract}

Keywords: acculturation, counseling ethics, ethics education, international students

Ethics is a complex discipline (Kitchener, 1986) because it "attempts to describe the innate complexity of constantly changing and constantly negotiated human relationships" (Hill, 2004, p. 183). Ethics education is more than the acquisition of ethical principles, codes of ethics, and standards of practice (Ametrano, 2014; Bashe et al., 2007; Handelsman et al., 2005). Handelsman et al. (2005) created an analogy between becoming an ethical psychologist and the acculturation process of immigrants. Similarly, the counseling profession has its own history, traditions, and values that shape its distinctive way of establishing and implementing ethical standards. As such, growing into an ethical counselor is a journey of developing a professional ethical identity as one experiences acculturation in counseling. 
The four primary strategies that immigrants typically use (e.g., Berry, 1997) separation, assimilation, marginalization, and integration - are readily transferrable to students' learning. If students place more value on their preexisting knowledge system (separation), students may experience greater difficulties in the acquisition of new knowledge. On the contrary, if they identify more with the new knowledge (assimilation), the old knowledge may be easily forgotten. When either the new or old is not welcomed by students (marginalization), it may produce the least learning productivity. However, if students are open to integrating and weaving both systems into a greater unit (integration), the resulting knowledge repertoire can be far richer. Extending the general acculturation model to specific discipline domains can assist educators in identifying students' acculturation strategies and making developmentally appropriate plans to meet students' needs, particularly for international students who experience acculturation both in the general sense and specifically within the subject area.

Three components play crucial roles in international students' counseling ethics acculturation: U.S. counseling ethics, students' home cultures as related to counseling ethics, and students' personal values and beliefs. Domestic counselors-in-training are mostly socialized in the U.S. culture wherein the ethics of the counseling profession is inherently imbedded. As such, the distance between U.S. counseling ethics and domestic students stems notably from individual differences, such as professional education, training experience, self-awareness, self-reflection, and growth environment (see Figure 1). For international students, an additional dimension (cross-cultural differences) may extend this distance if students' home cultures as related to counseling ethics are strikingly different than U.S. counseling ethics.

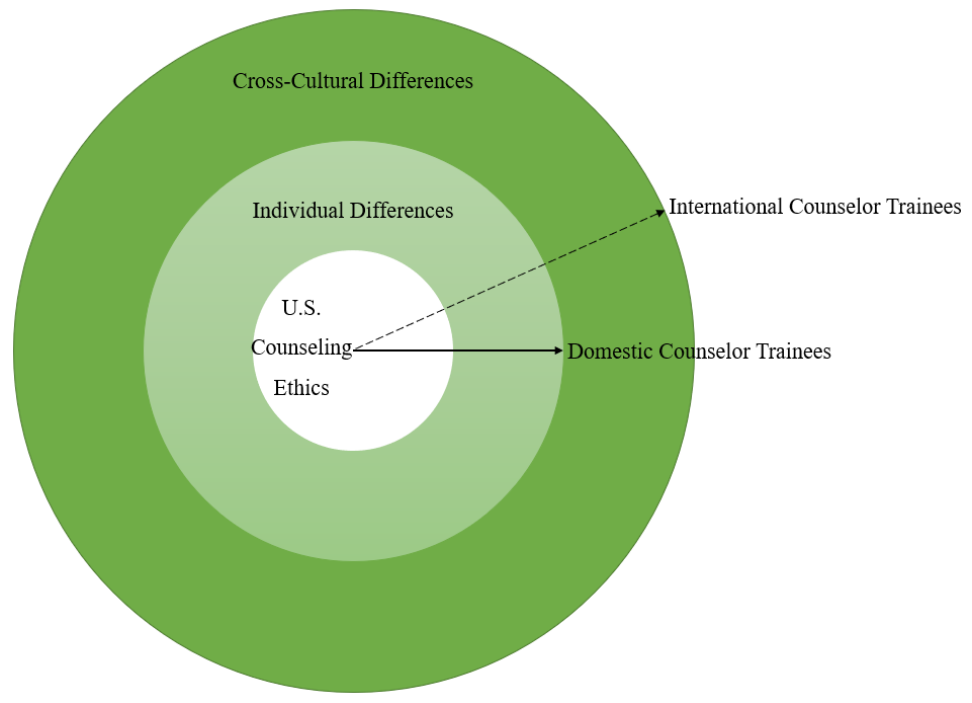

Figure 1. Two Student Groups with Varying Distances to U.S. Counseling Ethics 


\section{APPLYING THE ACCULTURATION MODEL: A CASE STUDY}

Provided the same ethical dilemma, the ethical decision-making process can vary drastically based on the acculturation strategy that is adopted. We will walk you through the four acculturation strategies in addressing an ethical dilemma that is adapted from a real situation. All identifiable personal information is removed. The order that these strategies are presented does not predicate or predict the actual acculturation process that each counselor-in-training may experience.

Wei is an international student from China and is pursuing a master's degree in school counseling in the United States. This fall semester, Wei works on his counseling practicum in a local elementary school. He provides weekly individual counseling to Jason who is a first grader originally referred to Wei by the student's teacher for social skills development. Jason is from a Hispanic family. In a regular psychoeducational session, Jason shared with Wei that he and his siblings were often hit by a belt and threatened with harm by their mother's previous boyfriend before they moved to the current state 2 years ago. But Jason emphasized that he and his siblings felt safe and happy in their current home with their mother and stepfather. After hearing this story, Wei had several competing voices in his mind. Different acculturation strategies could lead to different courses of action.

A person's acculturation strategy derives from a dynamic interfacing of two fundamental variables: the degree to which people preserve the values, beliefs, and norms from their cultures of origin and the degree to which they adopt the values, beliefs, and norms in the new host culture (Gottlieb et al., 2008; Handelsman et al., 2005). Depending on the extent to which Wei identifies with these two variables, respectively, Wei may resonate with one or some of the following strategies more than the other.

\section{Marginalization}

Upon hearing Jason's story about his past, Wei's first reaction may be that "hitting with a belt" and "threatening with harm" clearly signal child abuse. Based on the professional training he received through his coursework, he knows school counselors and educators are mandated to report child abuse. However, Wei does not have any evidence about these incidents that occurred 2 years ago in another state. Meanwhile, Wei may become aware that these incidents could be alternatively interpreted as parental discipline in the form of physical punishment, which may not need to be reported. Given the conflicting interpretations, Wei may not be able to come to terms with this issue very well. Wei then reports this ethical dilemma to his site supervisor. If Wei expects that his site supervisor will give him a direct answer, without thinking further about what could be done in the best interest of Jason, Wei would be going through the marginalization process. On the one hand, Wei would not identify with either U.S. counseling ethics or with his own personal ethics based on his original culture due to the conflicting conceptualizations. On the other hand, Wei would avoid professional consultation and expect his site supervisor to take responsibility in making an ethical decision. 


\section{Separation}

If Wei mostly identifies with his culture of origin with inadequate consideration about the counseling ethics in the United States, he may mentally debate more about whether "hitting with a belt" and "threatening with harm" should be defined as corporal punishment or physical abuse. In an international study of parents' perspectives on corporal punishment with children across nine countries, $17 \%$ of parents held the belief that it was necessary to use corporal punishment to raise the child (Lansford et al., 2010). In this same sample, $36 \%$ of mothers and $33 \%$ of fathers from China believed that it was necessary to use corporal punishment with boys, as opposed to $14 \%$ and $20 \%$, respectively, with girls. Given the relatively high acceptance rate of corporal punishment with boys by parents in Chinese culture, Wei's cognitive dissonance may lie mainly in defining the boundary between corporal punishment and physical abuse.

\section{Assimilation}

If Wei mostly identifies with the new counseling ethics culture, he would first probably consult with his site supervisor. Then, he would explore ways to define and identify child abuse. If this case warrants reporting, there would be several questions to think through. First, who should be the reporter? Second, who should be informed about this report? If Jason is deemed to be notified about this report, how should Wei address the issue of breaking confidentiality? If Jason's mother is to be notified, how could Wei start the conversation with her? Third, what information is needed to file this report? Additional parameters may further complicate this situation as well. For instance, what if Wei and his site supervisor have differed in opinion regarding whether reporting it is necessary? What if Jason and his mother do not feel comfortable to report this issue? In a word, the real-world environment translates the ethics language into tangible ethical dilemmas. If appropriately worked through, these dilemmas can potentially provoke growth in ethics-language learners, professionally and personally.

\section{Integration}

The integration strategy entails that Wei identifies with both his original and professional ethics cultures. Wei may have the multicultural sensitivity that "hitting with a belt" could still fall within the physical punishment realm in some cultures. However, the possibility that his student client encountered physical abuse cannot be overlooked. It is not unusual that there is an ambiguous boundary across different culture systems. Thus, it is important to reconcile one's personal values and professional values (Ametrano, 2014). The "bracketing" strategy (Kaplan \& Martz, 2014) upheld by the U.S. counseling profession is helpful in this integration process. To bracket does not mean to give up or to change a counselor's personal values; it makes a counselor become aware of their personal values and set those values aside when they are in conflict with values of the counseling profession (Kaplan \& Martz, 2014). To have this self-awareness for a counselor is to refrain from imposing 
personal values onto the client; the counselor would then be sensitive to the impact that their personal values, attitudes, beliefs, and behaviors may have on the client.

\section{IMPLICATIONS}

Conceptualizing ethics education as an acculturation process may help mitigate the stigma associated with inadequate learning (Handelsman et al., 2005), particularly among international students whose cross-cultural learning is tinted with difficulties and challenges ( $\mathrm{Li}$ et al., 2018; Li \& Liu, 2020). In addition, exploring the gap between the new and previous ethics cultures acknowledges the existence of trainees' personhood and the culture that they bring to the counseling profession, which may be more conducive to trainees' integration (Handelsman et al., 2005).

As the gatekeepers of the counseling profession, counselor educators need to be clear with counselor trainees that ethical standards are expected from every single member of the counseling profession, regardless of any preexisting values, beliefs, and customs that trainees may have. Accordingly, this same expectation would be applicable to international students who intend to pursue a counseling degree and to become a member of the counseling profession in the United States. Before prospective students are admitted to the counseling program, counselor educators should be explicit about the importance of abiding by and upholding the ethical standards of the counseling profession through various means (e.g., program advertisement and interviews). If students do not agree with the mission statement, ethics codes, and/or practice standards of the counseling program or profession, they have the autonomy to not be part of it.

Many international students grow up in cultures that are strikingly distinct from the U.S. culture. Thus, it is of great importance for counselor educators to be able to identify and address potential challenges should they arise during these students' ethics acculturation process. Ethics autobiography and reflection papers are great ways for students to voice their concerns and challenges (Bashe et al., 2007). One way to quickly identify students' needs is to expose students to various aspects of ethics at the beginning of a semester. Next, students can be encouraged to reflect on what stands out to them, thereby necessitating more attention. Later, instructors can collect students' feedback and reorganize the syllabi, if necessary, to ensure that students' needs will be addressed. Additionally, the instructor may facilitate critiques or debates of ethics codes (e.g., 2014 ACA Code of Ethics), which allow for juxtaposing differing opinions originating from both or more cultures so as to advance integration (Handelsman et al., 2005).

We have introduced the acculturation model to the counseling field, which sets the stage for further exploration about how this model can be applied to counseling ethics education. This calls for at least three directions in future research endeavors. First, future research can target the conceptual scaffolding of the ethics acculturation model in counseling. Second, researchers can use qualitative studies to examine international students' lived experiences of counseling ethics acculturation. Specifically, researchers may target international students' perceived factors that may assist or impede their acquisition of counseling ethics as related to their personal values and beliefs as well as those coming from their cultures of origin. Third, 
measures can be developed to assess different strategies that counselor trainees use in ethics acculturation. These measures will help understand different socialization processes of counseling ethics, if any, among counselor trainees across cultures.

The study of counseling ethics is more than the learning experience within a class; it is a lifelong learning journey. Counseling programs can instill ethics training across the curricula, in addition to a single ethics class, to ensure that students are exposed to counseling ethics discussions, develop their professional and ethical identities as counselors, and be engaged in ethical thinking that will benefit their entire professional lifespan.

\section{REFERENCES}

Ametrano, I. M. (2014). Teaching ethical decision making: Helping students reconcile personal and professional values. Journal of Counseling \& Development, 92(2), 154-161. $\quad$ https://doi.org/10.1002/j.15566676.2014.00143.x

Bashe, A., Anderson, S. K., Handelsman, M. M., \& Klevansky, R. (2007). An acculturation model for ethics training: The ethics autobiography and beyond. Professional Psychology: Research and Practice, 38(1), 60-67. https://doi.org/10.1037/0735-7028.38.1.60

Berry, J. W. (1997). Immigration, acculturation, and adaptation. Applied Psychology, 46(1), 5-34. https://doi.org/10.1111/j.1464-0597.1997.tb01087.x

Gottlieb, M. C., Handelsman, M. M., \& Knapp, S. (2008). Some principles for ethics education: Implementing the acculturation model. Training and Education in Professional Psychology, 2(3), 123-128. https://doi.org/10.1037/19313918.2.3.123

Handelsman, M. M., Gottlieb, M. C., \& Knapp, S. (2005). Training ethical psychologists: An acculturation model. Professional Psychology: Research and Practice, 36(1), 59-65. https://doi.org/10.1037/0735-7028.36.1.59

Hill, A. L. (2004). Ethics education: Recommendations for an evolving discipline. Counseling and Values, 48(3), 183-203. https://doi.org/10.1002/j.2161007X.2004.tb00245.X

Kaplan, D., \& Martz, E. (2014). Raising the bar for counselor educators. Counseling Today, 57(5), 26-27. https://www.counseling.org/docs/defaultsource/ethics/ethics nov 2014.pdf?sfvrsn=2

Kitchener, K. S. (1986). Teaching applied ethics in counselor education: An integration of psychological processes and philosophical analysis. Journal of Counseling \& Development, 64(5), 306-310. https://doi.org/10.1002/j.15566676.1986.tb01117.x

Li, D., \& Liu, Y. (2020). International counseling doctoral students' teaching preparation: A phenomenological study. Counselor Education and Supervision, 59(3). https://doi.org/10.1002/ceas.12184

Li, D., Liu, Y., \& Lee, I. (2018). Supervising Asian international counseling students: Using the integrative developmental model (IDM). Journal of International Students, 8(2), 1129-1151. https://doi.org/10.32674/jis.v8i2.137 
Lansford, J. E., Alampay, L. P., Al-Hassan, S., Bacchini, D., Bombi, A. S., Bornstein, M. H., Chang, L., Deater-Deckard, K., Giunta, L. D., Dodge, K. A., Oburu, P., Pastorelli, C., Runyan, D. K., Skinner, A. T., Sorbring, E., Tapanya, S., Tirado, L. M. U., \& Zelli, A. (2010). Corporal punishment of children in nine countries as a function of child gender and parent gender. International Journal of Pediatrics, 2010, 1-12. https://doi.org/10.1155/2010/672780

DAN LI, Ph.D., is an Assistant Professor of Counseling in the Department of Counseling and Higher Education at the University of North Texas. Her major research interests lie in the area of international counseling students and faculty, clinical supervision, and online or remote teaching and learning. Email: Dan.Li@unt.edu.

YANG AI, M.Ed., M.A., is an Assistant Professor in the Department of Counseling and Human Services at the University of Redlands, California. His main research interests lie in the area of counselor education and supervision, career counseling and development, and school counseling. Email: yang ai@redlands.edu. 